\title{
La organización del conocimiento al servicio de la interconexión entre las instituciones de la memoria y el turismo cultural
}

Knowledge organization for the interoperability among memory institutions and cultural tourism

\section{Francisco Javier GARcía MARco}

Universidad de Zaragoza, Instituto de Patrimonio y Humanidades, Pedro Cerbuna 12, 50009 Zaragoza (España), jgarcia@unizar.es

\begin{abstract}
Resumen
Se plantean las oportunidades para una alianza estratégica entre las industrias del turismo, la memoria cultural y la edición en el marco del despliegue de la web semántica y se aborda el papel central de la organización del conocimiento en este proyecto. Tras un análisis de la situación de cada una de estas industrias y de sus sinergias, se plantea la aportación de la organización del conocimiento en dos direcciones: mediante la aplicación del análisis de dominio a la modelización del sistema de colaboración, y del saber acumulado en la construcción de estructuras de conocimiento no redundantes y en el mapeo de sistemas conceptuales para la interconexión de sistemas, con especial atención a las posibilidades que ofrece la norma ISO 25964 . EI análisis se ejemplifica con un estudio de caso sobre la ecología informacional web del Camino de Santiago, y se presentan las lecciones aprendidas en el proceso.

Palabras clave: Organización del conocimiento. Turismo. Industria editorial. Instituciones de la memoria. GLAM. Web semántica. Interoperabilidad semántica. ODS. Camino de Santiago.
\end{abstract}

\section{Las nuevas necesidades del sector turístico: una oportunidad para las instituciones de la memoria y la organización del conocimiento}

Aunque la organización del conocimiento es por su propia naturaleza transdisciplinar - tanto por los aportes que recibe como por las áreas de aplicación-, es cierto que sus centros y áreas de práctica más formalizados y consolidados están especialmente ligados al campo de las instituciones de la memoria: bibliotecas, archivos, museos y sitios de referencia. Sin embargo, la explosión de la web, la proliferación de esquemas de organización del conocimiento fuera de la tradición de la disciplina (taxonomías, menús, anillos de sinónimos, ontologías, etc.) y la creciente interacción de especialistas de muy diversas disciplinas en torno al problema común de la organización del conocimiento - con sus diferentes puntos de vista y terminologías-, hacen necesario atender

\begin{abstract}
The opportunities for a strategic alliance among the tourism, cultural memory and publishing industries within the framework of the semantic web are discussed; and the central role in this project of knowledge organization as a discipline is addressed. After an analysis of the situation of each one of these industries and their potential synergies, the contribution of knowledge organization is proposed in two directions: through the application of domain analysis to the modelling of the whole collaboration system; and of its know-how in the construction of non-redundant knowledge structures and in the mapping of conceptual systems to system interoperability, with special attention to the possibilities offered by the ISO 25964 standard. The analysis is exemplified with the case of the web informational ecology of the Saint James' Way, and the lessons learned in the process are presented.

Keywords: Knowledge Organization. Tourism. Publishing industry. Memory institutions. GLAM. Semantic web. Semantic interoperability. ODS. Saint James' Way.
\end{abstract}

al nuevo universo de información digital e integrar viejos y nuevos saberes y prácticas.

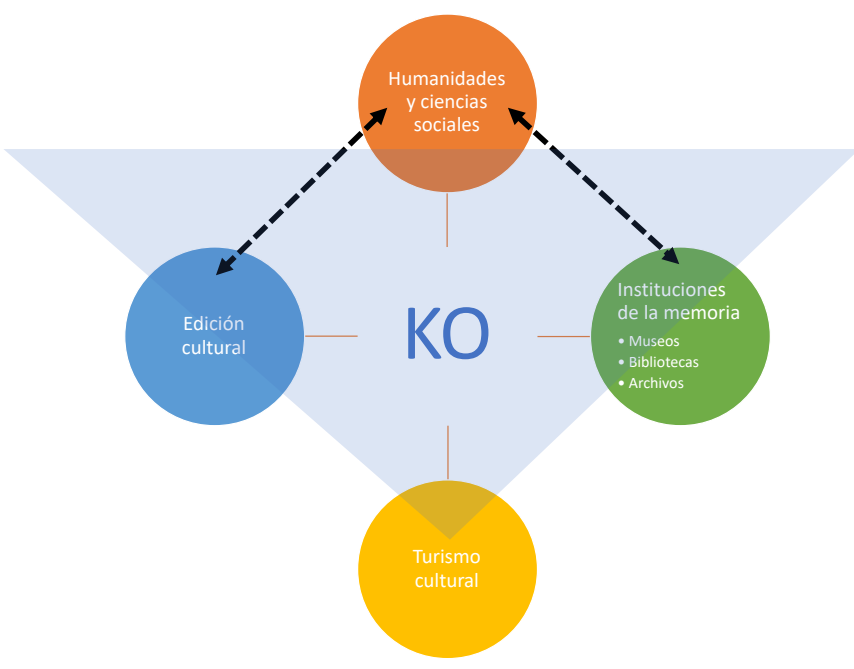

Figura 1. El potencial de la interoperabilidad a explorar 
En este contexto parece especialmente interesante la gran oportunidad que ofrece el acercamiento en el nuevo contexto digital entre una de las principales industrias de nuestra época -el turismo - y las instituciones de la memoria al servicio de unos turistas cada vez más educados y en busca de experiencias más personales, contextualizadas y genuinas.

\subsection{La importancia de la industria turística y su giro cultural}

Es difícil exagerar la importancia actual del turismo como industria (Lowry, 2017, p. xxxii). En 2019, antes de la crisis Covid-19, el World Travel \& Tourism Council (2021a) cifraba su contribución al PIB mundial en el 10,4\%, aportando nada más y nada menos que una decima parte de los trabajos del mundo. En España, país eminentemente turístico, la aportación del PIB dicho año ascendía al 14,1\% y la contribución al empleo al $14,4 \%$, esto es, casi uno de cada siete empleos (World Travel \& Tourism Council, 2021b).

El sector se encontraba en franco crecimiento, pues en marzo de 2015, cuatro años antes, las cifras se situaban un poco por debajo del $10 \%$ del PIC y de 1 de cada 11 puestos de trabajo (Lowry, 2017, p. Xxxii, siguiendo al WTTC). De hecho, entre 2014 y 2019 el turismo aportó uno de cada cuatro trabajos nuevos del mundo (World Travel \& Tourism Council, 2021a).

Aunque la pandemia le ha asestado un duro golpe bajando su contribución al $5,5 \%$ del PIB mundial y volviendo a las cifras de empleo de 2015 (1 de cada 11 trabajos), se espera una rápida recuperación en cuando mejore la situación sanitaria, para convertirse en "the key sector in driving the recovery of the global economy post COVID-19" (World Travel \& Tourism Council, 2020).

Pero el turismo no solo es una cuestión de interés económico, sino también de intercambio humano y realización personal. La actividad turística de tantos millones de personas y la rápida incorporación de los pueblos al turismo conforme alcanzan el suficiente nivel de ingresos (Fang, 2020) muestran la decisiva valoración que le otorgan tanto las personas como sus organizaciones. Además, es difícil negar su papel en el conocimiento de la cultura y las condiciones de vida de otras personas en un contexto de relación positiva, contribuyendo así de forma decisiva a través de la superación de los prejuicios y al establecimiento de interacciones positivas, la fraternidad y la paz, como, más allá de la indudable utilización propagandística del tópico y de la complejidad de los diferentes contextos, muestra la experiencia europea (Bechman, 2020, p. 402).
Esto es especialmente cierto en el caso del turismo cultural, que la World Tourism Organization (2012) define a grandes rasgos como el movimiento de personas por motivaciones culturales, como los viajes de estudio, los viajes para asistir a eventos culturales, lugares y monumentos, para estudiar la naturaleza, el folklore o el arte, y las peregrinaciones, incluyendo tanto el patrimonio material como inmaterial, lo que incluye aspectos como la música, la gastronomía, la lengua y otros aspectos de la vida cotidiana o de la cultura de élite. Es difícil desde esta definición que el turismo cultural no quede incorporado a casi cualquier viaje turístico en mayor o menor manera - no en vano sightseeing se traduce en muchos países hispanos como 'turistear'-, por lo que los académicos se han concentrado sobre todo en estudiar los tipos de turistas culturales, que varían en un continuo que va del ocasional o anecdótico al explorador o experto dedicado, normalmente en función de su motivación (McKercher and Du Cross, 2002; Petroman, 2013). En cualquier caso, el impacto del turismo en la valorización y preservación del patrimonio cultural tangible e intangible es, a pesar de constituir una relación compleja con sus claroscuros, es decisiva; y ese efecto se extiende por tanto a las instituciones y personas implicadas en esta tarea.

Ahora bien, bajo el impacto de la revolución en las tecnologías de la información -fundamentalmente, de la World Wide Web y las plataformas móviles - se ha ido produciendo un cambio muy importante en la naturaleza del turismo. En 2015 Xiang y sus colaboradores (2015) señalaban que se estaba produciendo "a growing "bifurcation" between traditional online travellers, i.e., those who use the Internet for standard travel products, and those who are beginning to adopt alternative channels and products in search of deeper and more authentic experiences". En términos de la matriz del Boston Consulting Group, aunque el mercado tradicional seguía constituyendo la "vaca", el ligado a las nuevas posibilidades que ofrece la Internet para localizar productos y experiencias más personalizados se estaba convirtiendo en la "estrella". Este viraje hacia un turismo más inquisitivo, educado y personalizado en busca de experiencias más profundas ligadas a la personalidad del turista ha llevado a expertos del campo a diagnosticar un 'cultural turn' en la industria (Dabbage 2018a, 55-56; 2018b).

El impacto radical que ha tenido la epidemia Covid en la actividad turística de masas se ha unido al creciente consenso internacional para una actividad económica sostenible concretado en la Agenda 2030 (Naciones Unidas, 2015) para enfatizar la necesidad de contar con alternativas al turismo de masas, basado en productos estándar 
igualmente masivos. En España y en otros países está contribuyendo también a este giro cultural del turismo la creciente preocupación por la despoblación de las áreas fundacionales de las actuales sociedades posmodernas, frecuentemente referido en nuestro país con el eslogan de la "España vacía". Finalmente, una población más diversa en inquietudes y fundamentos busca también cada vez más una experiencia turística más segmentada y auténtica desde su personal punto de vista.

\subsection{Las humanidades, las instituciones de la} memoria y la edición: un sector en redefinición

Durante la larga historia de la civilización, el esfuerzo de preservación del conocimiento y la evolución de las tecnologías de la información documental han ido resultando en diferentes especialidades profesionales, que en diferentes épocas de la historia también se han ido agrupando como consecuencia de las urgencias coetáneas. Así las bibliotecas se especializaron en época helenística desde los archivos, pero con las desamortizaciones de la época moderna surgieron cuerpos de funcionarios conjuntos que abordaban el conjunto del patrimonio desamortizado; igualmente, con el desarrollo tecnológico en época contemporánea las bibliotecas explotaron en multitud de "tecas" y archivos especializados, pero poco a poco las "tecas" se han ido reagrupando también bajo sus especialidades matriz bibliotecas y archivos - en forma de departamentos, colecciones y profesionales especializados. Con la explosión de la World Wide Web ha pasado algo semejante, y hoy en día las emergentes bibliotecas digitales vuelven a verse como un tipo de biblioteca especializado o parte de una biblioteca híbrida en vez de como una alternativa que cuestiona la trayectoria anterior o se separa de ella.

En el momento actual, desde un punto de vista meramente sincrónico, en los países avanzados, las leyes de depósito legal y las iniciativas de archivo privadas han hecho en las últimas décadas que todo el sector de la producción cultural -edición de libros y revistas, documentos de archivo, producción audiovisual, videojuegos, sitios web, etc.- - se fueran convirtiendo de iure en industrias culturales, pues a través de ellas se ha estipulado la preservación de sus contenidos y su inclusión en las instituciones de la memoria.

Desde un punto de vista diacrónico, ha sido la revolución digital la que ha acercado todo este sector que de nuevo se vuelve a ver como una unidad, especialmente desde el punto de los informáticos de sistemas de gestión del patrimonio y de los gestores de más alto nivel que se ven obligados a tomar una perspectiva amplia, ya sea por transversalidad de las aplicaciones y sistemas, ya por la jerarquización lógica de la política cultural. Como la digitalización se centra en la creación de representaciones documentales de todo el universo del patrimonio digital, contribuye a documentalizar la totalidad del ámbito de la preservación y difusión del patrimonio, que se aprecia como una unidad por parte de gestores, informáticos y profesionales de la información. Por fin, la perspectiva web además obliga a integrar los recursos hacia el usuario, que en general los ve como 'recursos digitales' al mismo nivel, lo que ha contribuido a la integración y compatibilización de esquemas de metadatos - si quiere, reglas de catalogación- y vocabularios de búsqueda sistemas de organización del conocimiento (SOC) - (Given and McTavish, 2010). Todos estos factores han favorecido que un término tan artificial como GLAM (Galleries, Libraries and Archives and Museums) haya ido ganando momento en los últimos años. (Esta tendencia se puede apreciar realizando una simple búsqueda retrospectiva con los términos TOPIC:(GLAM galleries libraries archives museums) -en plural para buscar artículos genéricos, filtrando otros sentidos de la palabra 'glam', notablemente la abreviatura de glamorous - en Web of Science (WoS), por ejemplo.

En el campo de la Information Science, algunos autores han escogido el término de instituciones de la memoria (Hjerppe, 1994; Hjørland, 2000) para referirse a ese amplio mundo de instituciones que se ocupan de la preservación del conocimiento, y efectivamente a nivel social a asegurar la memoria colectiva, y que se tomará también aquí como referencia (García Marco, 2010). También este término ha ido ganando momento en la última década, como se puede apreciar realizando la búsqueda TOPIC:("memory institutions") (en plural para buscar artículos genéricos sobre el tema) en WoS.

Ciertamente, desde un punto de vista más gerencial, se viene refiriendo a todas estas instituciones bajo el paraguas de la preservación del patrimonio, como instituciones patrimoniales, fijándose más en su dimensión material heredable entre las generaciones. Ese mundo también está sufriendo una gran transformación por el impacto de la globalización y las tecnologías de la información, y la desaparición de los modos de vida tradicionales. De hecho, la Unesco ha asumido con energía la incorporación del patrimonio inmaterial - esto es, todavía no codificado o almacenado de forma organizada - dentro de su campo de acción. El impacto de las nuevas tecnologías 
ha producido el despegue de un campo innovador al que se suele referir con el concepto de 'patrimonio digital' o 'digital heritage'.

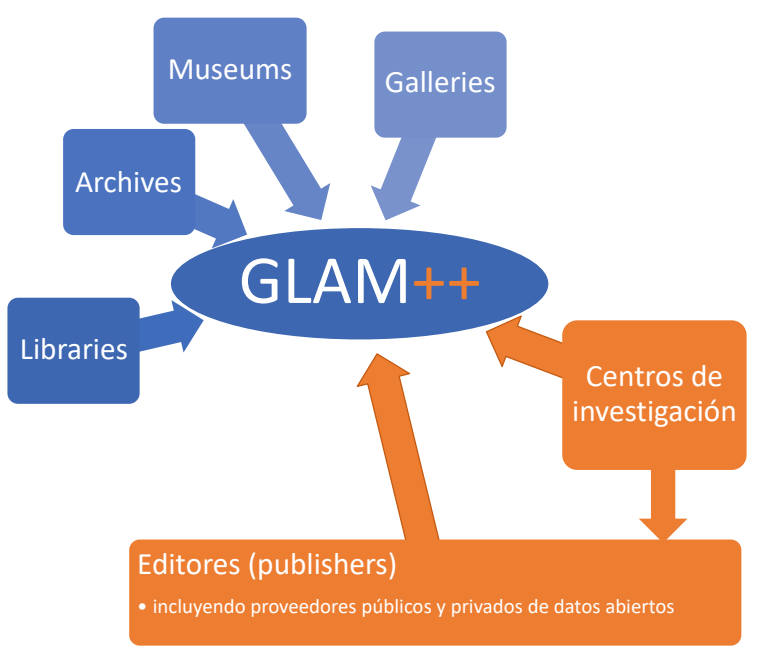

Figura 2. Un sector GLAM ampliado

Por otra parte, en este artículo se defiende que el dominio de trabajo de las instituciones de la memoria debe coordinarse estrechamente con los productores y transformadores de la información que aquellas custodian por varias causas. La primera razón es que la revolución digital está haciendo que mucha parte del trabajo de formateo y etiquetado de los datos y documentos se vaya desarrollando cada vez más dentro de las propias empresas editoras y de los propios centros de investigación, y todo hace pensar que este proceso aumente con la expansión de la web semántica y el movimiento de las publicaciones y datos abiertos enlazados. En segundo lugar, las empresas editoras y los centros de investigación - especialmente, pero no solo, los relacionados con las humanidades - son a la vez proveedores y consumidores privilegiados de las instituciones de la memoria, siendo incluso el origen de muchas ellas - por ejemplo, los archivos y bibliotecas académicas-, por lo que son sus aliados naturales en el proceso de cambio tecnológico en el que están inmersas. Por eso, en este artículo se propone el uso ampliado del acrónimo GLAM++, para denotar la necesidad e incorporar a estos dos grupos de instituciones al esfuerzo de normalización e interoperabilidad. Para este sector ampliado, la denominación de instituciones de la memoria parece especialmente adecuado, pues transciende la función patrimonial para abordar la investigación y el descubrimiento (que, por otra parte, muchas instituciones preservadoras también realizan). Por esta razón, los usaremos de forma indistinta con este significado a partir de ahora.
Por otra parte, la necesidad de competir en una economía global está haciendo que los fondos dedicados a la investigación se centren cada vez más en objetivos de rentabilidad económica, lo que pone en peligro disciplinas enteras que acumulan siglos de reflexión y desarrollo en el campo de las humanidades, y someten el mundo de las ciencias sociales a una extraordinaria presión de las modas del momento -forzadas por la dinámica política- que dificultan la acumulación orgánica del saber.

Para asegurar la supervivencia de estas disciplinas en estas condiciones, resulta necesario conectarlas con fuentes de financiación fuertes y estables compatibles con el nuevo énfasis en el desarrollo económico. En esta dirección, las industrias culturales y especialmente el turismo por su potencia económica son apuestas seguras, como muestran respectivamente el éxito de las series históricas y de los grandes museos en las últimas décadas. Ciertamente, será necesaria mantener la distinción entre ciencia aplicada y pura para moderar la instrumentalización de estas disciplinas (que, por otra parte, siempre se ha producido), pero al menos será más fácil mostrar su relevancia económica y social y asegurar su sustento económico.

1.3. Oportunidades para una alianza estratégica entre el sector de la memoria cultural y del turismo

Se ha discutido en las páginas anteriores como tanto el mundo del turismo como el de las humanidades y la memoria cultural están sometidos a presiones sociales, económicas y tecnológicas que ponen en cuestión la eficacia de su gestión actual. La globalización pone en peligro con su poder de aculturación la pervivencia del patrimonio cultural, pero a la vez despierta en las masas cada vez mejor educadas un hambre por el conocimiento de sus raíces lejanas y el encuentro con otras culturas y formas de vida. Las tecnologías de la información actúan como un enorme nivelador al difundir los consensos alcanzados por los poderosos a naciones y pueblos en rápida transformación, pero a la vez permiten la gestión, preservación y difusión de enormes cantidades de información, y su descubrimiento de forma altamente personalizada.

La idea es que, a medida que la información patrimonial y el conocimiento humanístico se exprese con los nuevos formalismos que permiten su procesamiento automático con fines diversos - según los principios y estándares del movimiento de datos abiertos enlazados-, toda esa información se ponga al servicio (y también sirva 
de contraste y contexto, por qué no) de la producción cultural y de la explotación turística del patrimonio cultural material e inmaterial. Por su parte, el sector del turismo podrá beneficiarse de información más contextualizada, personalizable, contrastable y genuina. Por otro lado, el sector GLAM++ podrá "mejorar su visibilidad y relevancia a través de una contribución incontestable, aplicada y práctica al desarrollo económico y social" (García-Marco, Galindo, Lasala y López-delRamo, 2020), pensando especialmente en la necesidad de afrontar la rápida decadencia y despoblación de los espacios rurales y de las ciudades pequeñas que han constituido la base de nuestras culturas, y que no es sino manifestación de una ola imparable que va transformando el mundo entero desde que empezara a manifestarse en la Inglaterra de la industrialización (Laslett, 1965).

Las fuentes y el saber humanístico "datificados" pueden alimentar el torrente de datos que un turismo enriquecido, preparado y acompañado por páginas web inteligentes y aplicaciones de realidad aumentada y virtual necesita para adaptarse a turistas cada vez más preparados, que buscan una experiencia personalizada y enriquecida, dándoles acceso al nivel de complejidad que necesitan y para el que están preparados. Gracias a este aporte de información a través de dispositivos móviles, los espacios físicos se convierten en entornos accesibles, comunicables, didácticos, recomendables, contrastables y comparables, permitiendo al visitante sumergirse en las lecciones ocultas que encierran, tanto en el momento de seleccionar los destinos, como en la preparación del viaje, la propia visita, y la documentación y comunicación de la experiencia.

La arquitectura básica de este esfuerzo se sintetiza en la Figura 3: se trata de movilizar las fuentes culturales y de infraestructuras turísticas teniendo en cuenta la segmentación de los usuarios para proporcionarles un mensaje ajustado a sus necesidades a través de diversas aplicaciones y plataformas de comunicación con el objeto de que puedan alcanzar una experiencia enriquecida en las diferentes fases de la actividad turística.

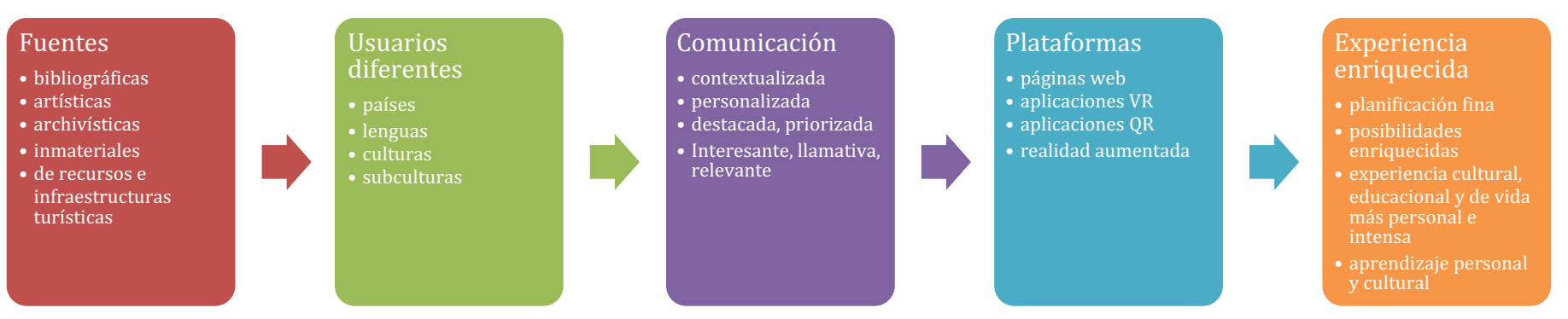

Figura 3. Una visión ganar-ganar para turistas, destinos, agentes turísticos e instituciones de la memoria

En conclusión, las humanidades y las instituciones de la memoria se pueden beneficiar recíprocamente de la llegada de recursos para hacer posible este esfuerzo y, en general, facilitar la financiación de la investigación básica al conectarla mejor con sus usos económicos potenciales. Esto parece especialmente importante en una época en que el acelerado cambio cultural, las luchas político-culturales entre identitarios y globalistas y la sucesión de crisis económicas $(2008,2020)$ han contribuido a poner en peligro la inmediata relevancia y financiación de la cultura frente a las urgencias económicas y sanitarias del momento a lo largo de un periodo muy prolongado.
1.4. La organización del conocimiento al servicio de la integración de las industrias culturales

La organización del conocimiento puede contribuir de una forma sustancial a la visión de unas instituciones de la memoria y servicios turísticos conectados de forma más estrecha y productiva. A nuestro entender, puede hacerlo fundamentalmente de dos maneras. En primer lugar, contribuyendo a hacer inteligible el esfuerzo a través de una de sus metodologías más propias, el análisis de dominio (Hjørland \& Albrechtsen, 1995; Hjørland, 2017), aplicado sobre todo sobre el conjunto de sitios web en los que se expresa el quehacer de las instituciones turísticas y de la memoria, entendidos como ecología informacional (García Marco, 2015). En segundo lugar, contribuyendo a conectar entre sí a los diferentes 
agentes gracias a la sólida compresión de los principios universales y compartidos de la clasificación que la organización del conocimiento como disciplina aporta (Ranganathan, 1937; Dahlberg, 1995) y de los instrumentos para compatibilizar estructuras conceptuales para hacerlas interoperables (Zeng, 2019). Esfuerzo que debe abordarse actualmente en el marco de la web semántica en cuanto que infraestructura capaz de conectar datos de forma a la vez procesable automáticamente por las máquinas e inteligible por los humanos, apoyándolo desde la capa de la web semántica que le es más propia a la organización del conocimiento: la ontológica. Las dos siguientes secciones del artículo están específicamente dedicadas a abordar sendas vías.

\section{La modelización de la ecología informacional del turismo cultural: agentes y organizaciones del conocimiento en concurrencia}

El concepto de ecología aplicado al mundo de la información y la comunicación puede ser extraordinariamente fructífero, y tiene una tradición de varios decenios en el campo de la ciencia de la información (Hubermann 2001; Shim and Lee 2006; Sebastiá 2008). Igual que sucede en el ámbito de los ecosistemas biológicos, los diferentes sistemas de información que coexisten en un sistema social establecen relaciones de coexistencia, cooperación y competencia entorno a las necesidades de información presentes en él, formando un sistema complejo. Esto se aprecia especialmente en el mundo de la Internet, en el que resulta relativamente fácil estudiar con métodos informétricos (webmetrics) su evolución. En definitiva, una ecología informacional se puede definir como un conjunto de organismos que interaccionan entre ellos y con su ambiente para resolver necesidades de información, y cuyo análisis cuidadoso deber ser siempre el paso previo de cualquier intervención futura. Estas ecologías informacionales que evolucionan de una forma propia contrastan con los sistemas de información diseñados, con las arquitecturas informacionales; pero, por supuesto, también pueden ser intervenidas y normalizadas hasta cierto punto, como sucede por ejemplo con otros sistemas abiertos como los sistemas eléctricos o de comunicaciones.

Un buen ejemplo es la información sobre el Camino de Santiago en la web, en la que se puede apreciar con nitidez ese conjunto de elementos en interacción dinámica en función de un objetivo (comunicarse con los usuarios interesados en la ruta, desde diferentes puntos de vista) y también sus disfunciones (López del Ramo and García Marco, 2018). En la figura 4 se pueden apreciar sus componentes fundamentales agrupados por sectores, cada uno haciendo énfasis en los servicios que más les interesa ofrecer.

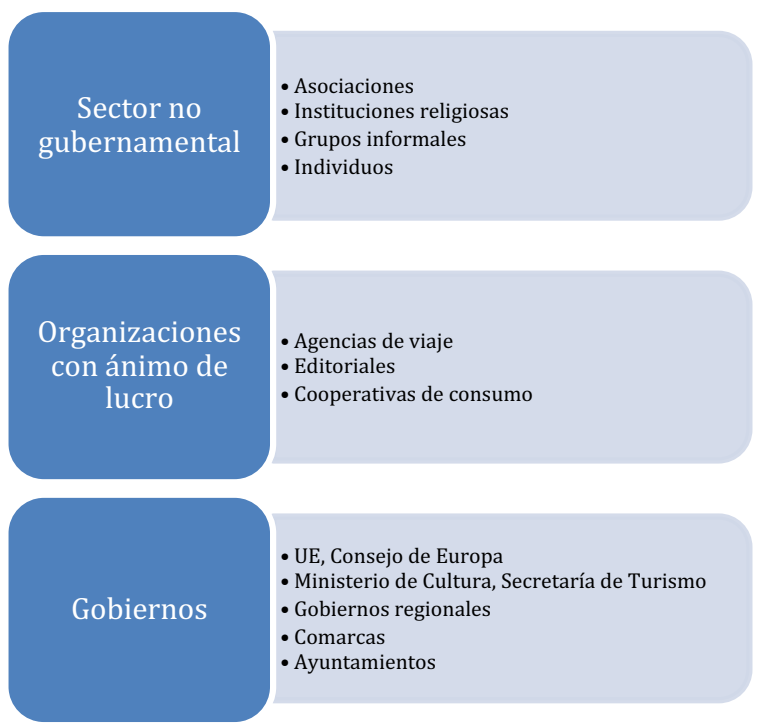

Figura 4. Agentes de la ecología informacional del Camino de Santiago

Desde el punto de vista de los objetivos de este artículo, se trataría de incorporar a esta ecología surgida de una manera natural el input de las instituciones de la memoria en función de los intereses de los turistas (usuarios). Quedarían por tanto tres subsistemas a analizar —entrada desde las instituciones de la memoria, mediadores de información turística, y turistas- que se van a analizar en detalle en las tres siguientes subsecciones desde el punto de vista de su interoperabilidad semántica.

\subsection{Los creadores de información:}

las instituciones de la memoria

Quizá el mayor reto de movilizar la información de las instituciones de la memoria hacia el sector turístico sea la gran complejidad y diversidad de los esquemas de metadatos -en parte paliado por la posibilidad de utilizar esquemas de "máximo común divisor" como Dublin Core- $y$, centrándonos en lo que nos ocupa en este artículo, los SOC utilizados. Por eso, en este trabajo la cuestión se ha dividido en dos fases: en primer lugar, conocer los SOC utilizados en cada tipo de instituciones de la memoria; $y$, en segundo, lugar explorar estrategias para su interoperabilidad.

Las bibliotecas han sido durante décadas y siguen siendo el sector más avanzado en la estandarización, aunque archivos y museos están acercándose rápidamente bajo la presión y el incentivo de la digitalización y la publicación de sus fondos en Internet. Las bibliotecas comparten un 
esquema de metadatos muy elaborado y normalizado (la familia MARC21 y las DRA), y en menor medida un conjunto de SOC en gran parte complementarios (sistemáticos y alfabéticos), pero también en competición: LCC, DC, CDU, entre otros, por la parte de los SOC sistemáticos; y LCSH, RAMEAU, EMBNE, entre otros, por la parte de los sistemas de encabezamientos de materia, y algo semejante sucede con las autoridades de persona, entidad y lugar. Sin embargo, programas de mapeo entre todos ellos están en curso desde hace años y en muchos casos muy avanzados (Slavic, 2011; Zen, 2019).

Otros problemas surgen cuando se intentan utilizar para conectar los recursos con las necesidades de los mediadores turísticos y los propios turistas. Mientras que los encabezamientos de materia suelen ser suficientemente específicos, las clasificaciones no lo son tanto por su alcance muy general y fundamentalmente disciplinar. Los encabezamientos de lugares, entidades y personas resultan ser con mucho los más específicos.

Esto se aprecia fácilmente con el ejemplo del Camino de Santiago (García, Galindo, Lasala y López, 2020). Por lo que respecta a las clasificaciones, si nos centramos en la más usada en su ámbito geográfico, se observa el Camino no dispone una clase en la CDU: normalmente se clasifica en la clase de Geografía Regional (913), y en menos ocasiones en la de Rutas (656.022) o en las muchas y dispersas clases disponibles para Viaje (por ejemplo, 338.48-12, 656.022.33), ya que transporte y turismo se encuentran en clases diferentes. Para darle especificidad a unas clasificaciones tan generales, en las bibliotecas españolas se suele añadir una faceta de país $(44+460$, Francia y España, por lo de Camino Francés, y aunque el Camino no esté limitado a estos países). Los bibliotecarios de la Biblioteca Nacional de España haciéndose cargo del problema, han venido añadiendo a los recursos relevantes la cadena "Camino de Santiago" entre corchetes después de los códigos de país, pero como se observa en los catálogos colectivos del país esta es una solución particular de esta institución. Por el contrario, por lo que respecta a los sistemas de encabezamientos de materia, aunque tampoco existe un encabezamiento específico, al menos son fácilmente reconocibles y, si fuera necesario, mapeables:

- EMBNE: Peregrinaciones cristianas - Santiago de Compostela

- LCSH: (Christian pilgrims and pilgrimagesSpain-Santiago de Compostela)

RAMEAU: [Pèlerinages chrétiens-EspagneSaint-Jacques-de-Compostelle (Espagne)]
El otro problema que plantean los recursos bibliotecarios es que ofrecen documentos completos -información sistematizada y organizada como un todo-, lo cual resulta muy interesante para ayudar al turista a documentarse en general o sobre ciertos aspectos concretos. Por el contario, no permiten un acceso rápido a consultas concretas - exigen un costoso ojeo-; y, sobre todo, no permiten agregar y manipular datos, que son la materia prima de las decisiones turísticas en la Internet. El costoso proceso de convertir libros, artículos y documentos audiovisuales en datos estructurados llevará años y necesitará el concurso de los centros de investigación y de las editoriales, como hemos comentado antes.

Sin embargo, los museos -lógicamente nos referimos a los que tienen los medios necesariosdescansan para su complicada gestión en bases de datos muy analíticas, que les han servido para situarse entre las instituciones de la memoria en la vanguardia de la aplicación de las tecnologías semánticas. En el campo de los museos ha surgido también una sofisticada propuesta ontológica - CIDOC CRM-, que ha transcendido su ámbito para convertirse en una referencia fundamental en la publicación como datos enlazados de los recursos digitales de las instituciones de la memoria en su conjunto. En el ámbito museístico han surgido también SOC muy analíticos y bien organizados como el Art and Architecture Thesaurus (AAT) o el Iconclass, entre otros.

La situación del mundo archivístico respecto a la propuesta de una interconexión más estrecha entre las instituciones de la memoria y el sector turístico es más distante. Los turistas, excepto el tipo deliberado que se considerará más tarde, raramente interactúan directamente con los fondos y documentos, salvo en exhibiciones, de forma muy parecida a como lo hacen con los objetos museísticos. El uso de documentos de archivos por parte de los turistas es secundario respecto a otros activos, pues no se emplea directamente en la planificación del viaje y en las decisiones turísticas. Como es bien conocido, los usuarios de archivos son fundamentalmente investigadores y administraciones y personas con necesidades de prueba legal. Además, los archivos tienen formas de organización del conocimiento más idiosincrásicas, basadas en el principio de proveniencia y agrupación natural de los fondos, aunque se dispone también de alternativas más transversales como la clasificación funcional. Tesauros y encabezamientos tienen un papel menor, pero su uso está creciendo transversalmente en el conjunto de las instituciones de la memoria sobre todo en lo que se refiere a los sistemas de autoridades de nombres de persona, entidad y lugar. En cualquier caso, y a pesar de las razones antedichas, 
la interrelación de los documentos y fondos de archivos -y de los datos que contienen- no debería faltar en la estrategia que se está planteando, especialmente pensando en los turistas más deliberados y en la producción de exhibiciones y contextualizaciones virtuales y de realidad aumentada.

Como se ha señalado, el sector de la producción editorial -impresa y audiovisual- tendrá que transformarse en los próximos años para acomodarse dentro del nuevo marco de transmisión del conocimiento al que apuntan las tecnologías semánticas y sociales, con sus frentes más visibles en la actualidad: los datos enlazados, el big data y las aplicaciones de la inteligencia artificial. Para que esto sea posible los autores y los editores tienen que proveer sus documentos en forma anotada, de manera que sus diferentes niveles de datos sean accesibles para su combinación y procesamiento automático. Las bibliotecas y sus esquemas de metadatos también se tendrán que ir transformado para facilitar y preservar este nuevo mundo de información. La tendencia actual a la convergencia de medios y reutilización de contenidos favorecen estos procesos de marcado profundo dentro de los proyectos editoriales.

\subsection{Los mediadores de información: DMOs, asociaciones, empresas y particulares}

En el caso de la información turística, y aunque en ocasiones las instituciones de la memoria se comunican directa y eficazmente con los turistas -notablemente los museos y centros de interpretación-, su circulación se produce fundamentalmente a través de los mediadores turísticos, conocidos técnicamente como organizaciones de marketing o comercialización de destinos (en inglés, destination marketing organizations, DMOs) —esto es, las oficinas de promoción turística de los estados, regiones, y especialmente comarcas y municipios-, y cada vez más a través de las agencias de viaje en línea y sus redes sociales específicas (Xiang et al., 2015), que compiten cada vez con más fuerza con las agencias tradicionales, que también se han ido volcando en el nuevo medio. Además ciertas empresas, especialmente editoriales especializadas en turismo y patrimonio funcionan también en la práctica como DMOs y servicios de documentación y comunicación de los DMOs oficiales.

Por fin, las asociaciones de expertos y aficionados en cuestiones culturales, así como ciertas personas individuales también juegan un papel importante en la información turística cultural. En el caso de nuestro ejemplo son notablemente importantes las asociaciones de amigos del Camino de Santiago, y autores que mantienen blogs de mucho interés. La internet ha permitido la democratización de la publicación, y actualmente pequeñas organizaciones y personas muy dedicadas pueden tener una presencia global notable.

La organización del conocimiento para los mediadores de información turística tiene dos dimensiones: una interna, relacionada con la gestión del conocimiento de la organización (o del individuo) en sus diferentes aspectos -captura o representación del conocimiento en información, preservación, recuperación, y transformación de la información en conocimiento- a través de un SAC corporativo o personal; y otra externa, dirigida a comunicar de forma organizada la información de interés a los turistas, de manera que sean informados, puedan convertir esa información en conocimiento y finalmente tomar un conjunto de decisiones turísticas que se concreten en un viaje. La comunicación externa se hace normalmente a través de sitios web y plataformas sociales, aunque cada vez más se proponen a los usuarios también aplicaciones (app) móviles crecientemente sofisticadas. En los sitios web se utiliza para organizar el conocimiento fundamentalmente taxonomías que se manifiestan sobre todo en los menús de usuario; y en los sitios sociales sobre todo folksonomías y, en algunos casos, taxonomías ad hoc. En las aplicaciones web y móviles se detecta también el uso de ontologías subyacentes en los casos más avanzados, sobre todo en los sistemas de recomendación (Abrahams \& Dai, 2005; Li, Buhalis \& Zhang, 2013; Grün, Neidhardt \& Werthner, 2017).

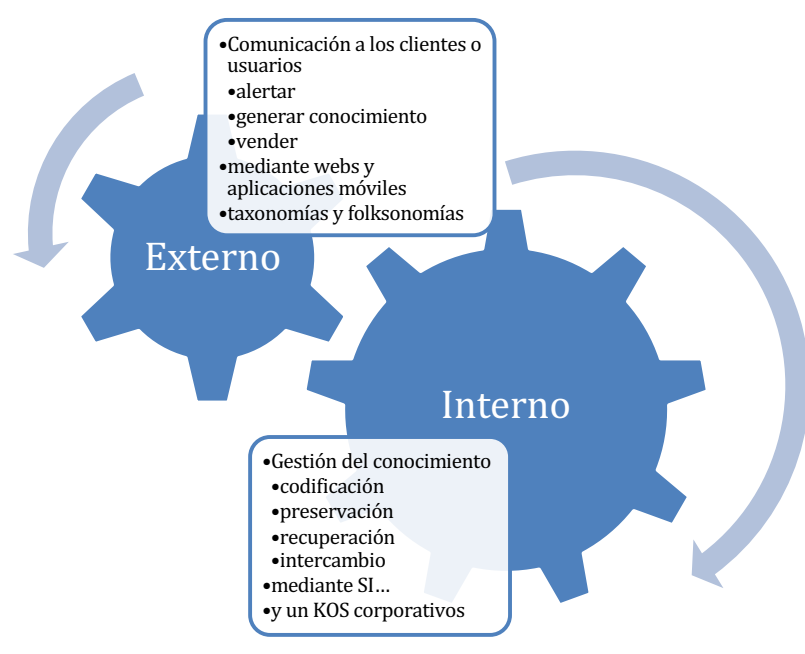

Figura 5. Las dos dimensiones de la organización del conocimiento en los mediadores turísticos

Aunque ambas dimensiones -que coinciden con la tradicional distinción entre intranet, internet 
(y extranet) - tienen que estar conectadas para evitar redundancias e inconsistencias, cada una debe ser abordada en sus propios términos. Los contextos internos son mucho más especializados conceptualmente, idiosincrásicos terminológicamente y se organizan fundamentalmente a partir de las funciones y la estructura organizacional. Sin embargo, los medios externos tienen que ser capaces de comunicarse eficazmente con el usuario, acercándose a su(s) esquema(s) natural(es) de organizar el dominio y a sus actividades típicas. Sin embargo, y a pesar de su lógica proximidad, muchas veces se aprecian disfunciones en ambos sentidos: o ambas dimensiones están construidas por separado, sin comunicarse y estructurarse adecuadamente; o, por el contrario, una absorbe a la otra, anulándola y frustrando sus objetivos (Figura 6, García, Galindo, Lasala y López, 2020). En particular, es muy frecuente que la taxonomía corporativa se convierta en la base del sitio web dedicado a los turistas (López del Ramo and García Marco, 2018) o que se centre básicamente en los productos ofrecidos; aunque también se encuentran ejemplos de sitios web muy bien diseñados desde una perspectiva centrada en el usuario (Tabla I).

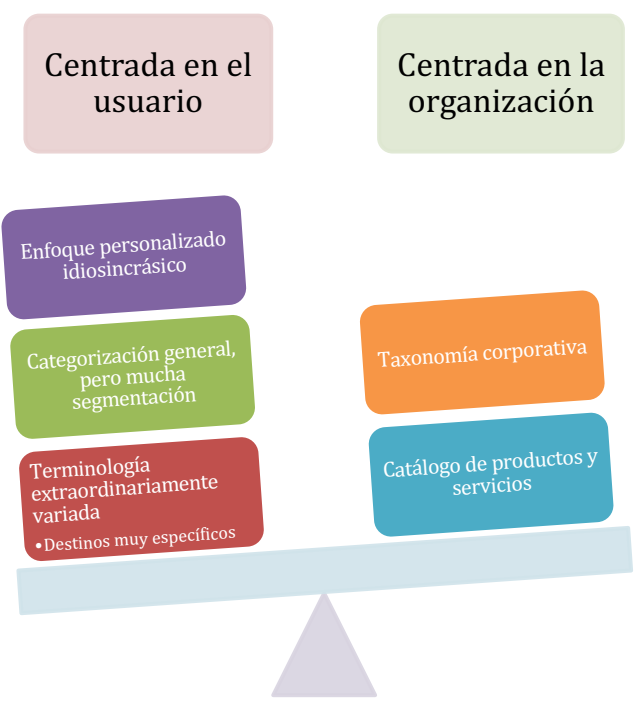

Figura 6. Enfoque centrado en el usuario frente a centrados en la organización en el diseño de webs turísticos

\begin{tabular}{|c|c|c|c|c|}
\hline Dirección & caminodesantiago.gal & turismocastillayleon.com & caminodesantiago.org & Santiagoways.com \\
\hline $\begin{array}{l}\text { Descripción, } \\
\text { sector }\end{array}$ & $\begin{array}{l}\text { Sitio orientado al turista del } \\
\text { Gobierno de Galicia }\end{array}$ & $\begin{array}{l}\text { Sitio del Gobierno de } \\
\text { Castilla y León }\end{array}$ & $\begin{array}{c}\text { Sitio de la Federación } \\
\text { Española de Asociaciones } \\
\text { Jacobeas }\end{array}$ & Agencia de viajes \\
\hline $\begin{array}{l}\text { Conocer, } \\
\text { motivar }\end{array}$ & Descubre & & & St James' Way \\
\hline $\begin{array}{l}\text { Preparación del } \\
\text { viaje (equipo) }\end{array}$ & Prepárate & $\begin{array}{l}\text { Consejos } \\
\text { A pié } \\
\text { En bicicleta } \\
\text { A caballo }\end{array}$ & Consejos & $\begin{array}{l}\text { Consejos } \\
\text { A pie } \\
\text { En bicicleta } \\
\text { Grupos }\end{array}$ \\
\hline Ruta & Planifica tu viaje & $\begin{array}{c}\text { Equipamiento } \\
\text { 'Credencial’ } \\
\text { 'Turismo España' GPS }\end{array}$ & Camino & Caminos [cada uno] \\
\hline En Camino & Durante el Camino & $\begin{array}{c}\text { 'Correos' } \\
\text { Información sanitaria } \\
\text { Reciclado }\end{array}$ & Servicios & 'Nuestros' servicios \\
\hline \multirow[t]{2}{*}{ Cultura } & Santiago y Galicia & & Scriptorium & Historia \\
\hline & $\begin{array}{l}\text { Conocimiento e } \\
\text { investigación }\end{array}$ & & Links & \\
\hline $\begin{array}{l}\text { Promotor, } \\
\text { marca }\end{array}$ & Xunta de Galicia & Contacto & Noticias de la Federación & $\begin{array}{l}\text { Firma, Nuestro equipo, } \\
\text { Contacto, Noticias }\end{array}$ \\
\hline
\end{tabular}

Tabla I. Categorías principales de cuatro sitios de diferente tipo sobre el Camino de Santiago

2.3. Los consumidores de información: los turistas

El mundo de los turistas - los consumidores finales de la información- no es menos complejo que el de los productores y mediadores de infor- mación (Figura 7). Aunque las necesidades de información generales y específicas son muy semejantes - planificar y contextualizar el viaje, resolver problemas prácticos, buscar datos específicos y navegar las fuentes-, no todos los turistas las persiguen con igual interés ni eficacia, ni en general ni en contextos concretos. 


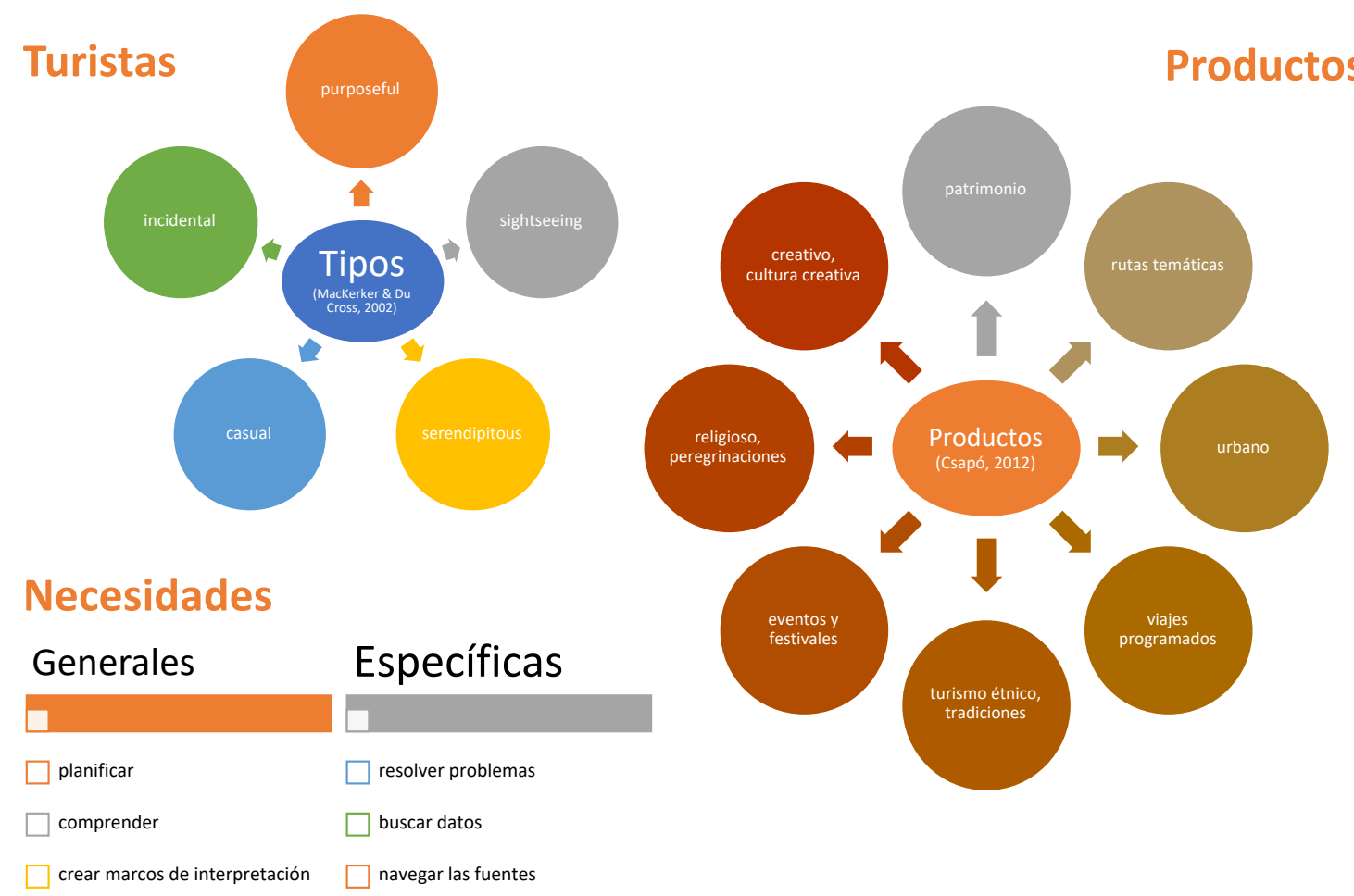

Figura 7. Modelización del turista y el turismo cultural: turistas, necesidades y productos

Esto es así porque, como en otras actividades humanas, los sujetos están muy segmentados en cuanto a intereses, capacidades y dedicación efectiva. Esto se aprecia tanto en las categorizaciones que se han propuesto de los turistas en cuanto a los aspectos culturales, como a los productos de marketing que se les ofrecen y que en sí mismos son identificativos de una segmentación comercial de los turistas. Así, en cuanto a los turistas y para el caso estricto del turismo cultural McKercher y Du Cross (2002) han identificado cinco tipos diferentes: deliberados (purposeful), turísticos (centrados en las atracciones), afortunados (serendipitous), casuales e incidentales; mientras que Csapó (2012) fue capaz de identificar siete tipos diferentes de productos de turismo cultural diseñados para distintos tipos de turistas: turismo patrimonial; rutas temáticas culturales; turismo cultural urbano, excursiones culturales; turismo étnico y tradicional; turismo de eventos y festivales; turismo religioso y rutas de peregrinaje; y, finalmente, cultura creativa y turismo creativo.

Esta diversidad se refleja en la variadísima terminología utilizada por los usuarios en las búsquedas y en su desconexión (Xiang et al. 2009) con las propuestas de organización del dominio que realizan los sitios web turísticos, más allá de las típicas categorías generales del campo (acceso, alojamiento, gastronomía, sitios que ver, contexto histórico, etc.). Como señalan Xiang y sus colaboradores (2009) "el dominio completo es extremadamente rico y en gran parte idiosincrásico [...] con muchos detalles dependientes del destino". Afortunadamente, el lenguaje de los turistas puede ser explorado en profundidad a partir de los contenidos que ellos crean -blogs, posts y reseñas (reviews) (Gretzel, Hwang and Fesenmaier 2006)-; pero, por el contrario, todo este mundo es difícil de abarcar, modelizar y presentar organizadamente a los usuarios. Todo ello hace pensar que, con el tiempo, el trabajo de organizar un dominio tan complejo solo se puede ir resolviendo parcela a parcela en concurrencia por diferentes agentes, y que los abordajes generales servirán para integrar este complejo mundo pero que un resultado global sólo puede ser fruto del trabajo de muchos años.

Por otra parte, la superación de esta brecha entre los usuarios y la información turística a través de la modelización conceptual de ámbitos específicos ha sido objeto de un gran interés por especialistas en inteligencia artificial durante las dos últimas décadas y se ha convertido en un campo consolidado de investigación bajo la denominación de sistemas de recomendación turística (Grün, Neidhardt and Werthner, 2017). Estos sistemas se orientan sobre todo a establecer correspondencias de destinos y recursos turísticos con perfiles 'ontológicos' de los turistas a partir de características de personalidad y preferencias de viaje. La conexión de estos sistemas con fuentes 
documentales y bibliográficas requerirá un trabajo muy detallado y cuidadoso, especialmente tras superar los intereses básicos de los turistas para alcanzar el difícil territorio del aprendizaje, el descubrimiento y la inmersión cultural; pero constituye un campo muy prometedor de investigación.

\section{La ruta hacia la interoperabilidad semántica}

Teniendo en cuenta el análisis anterior, se considera que, para conseguir una integración de los recursos culturales con los intereses de los turistas en el marco de las tecnologías semánticas, es necesario avanzar en al menos tres frentes: a) avanzar en la modelización de los intereses de los usuarios de manera que se abarque de forma a la vez comprensiva e inteligible su diversidad; b) identificar las tecnologías disponibles más adecuadas para la implementación del puente ontológico; y c) proponer metodologías que permitan abordar el problema por partes y sectores, pero con una perspectiva global, auténticamente integradora, $y$ que sea factible, sin sucumbir ante la evidente complejidad de la tarea. A continuación se analizan estos tres objetivos con más detalle.

\subsection{La modelización del usuario y sus mediaciones}

Como hemos visto en la sección 3.3 las perspectivas de los turistas y de las organizaciones turísticas sobre su actividad son extraordinariamente diversas y muy sujetas a las especificidades tanto del turista como del destino. Más allá del inventario imprescindible de los servicios turísticos - desplazamiento, alojamiento, manutención, actividades de ocio, contexto, servicios básicos (salud, seguridad, servicios sociales, etc.) - y su segmentación económica (ofertas, última hora, etc.), es necesario un modelo del turista que permita también incorporar las dimensiones experienciales y de autorrealización que una aproximación cultural al turismo requiere. Quizá para esta misión resulte especialmente útil la pirámide de las necesidades humanas propuesta por Maslow (1954), que permite incluir tanto las más básicas - desplazamiento, alojamiento, comida y bebida, seguridad)—, como las sociales (identidad, relación) y las de autorrealización (creación de sentido, cultura popular y alta cultura, sabiduría y espiritualidad).

Lógicamente, una ontología de las necesidades humanas carece de la suficiente especificidad para representar un dominio concreto como el turismo salvo en sus niveles más generales, y fundamentalmente como una estructura contrastiva: esto es, de comparación y evaluación. Para las especificidades del campo, contamos con al menos cuatro fuentes: a) el bruto de las textos, imágenes, vídeos y comentarios de las páginas web y redes sociales, que pueden ser analizados como corpora y proporcionar terminología e iconología; b) las numerosa taxonomías desarrolladas para los sitios web turísticos, ya sea estrictamente -como taxonomías de CMS - o de forma subyacente y apreciable fundamentalmente en los menús de usuario, que proporcionan también estructuras jerárquicas y auténticos mapas de conceptos; $c$ ) las ontologías que se están realizando, algunas específicamente dirigidas a modelar las necesidades de los usuarios (Li, Buhalis and Zhang, 2013), que aportan relaciones complejas; y c) algunos lenguajes documentales muy específicos como el tesauro multilingüe de la Organización Mundial de Turismo (World Tourism Organization, 2001), que pueden proporcionar un marco común, ya sea de forma contrastiva o normativa.

\subsection{La modelización semántica y la vía ISO 25964}

El despliegue normativo de la web semántica está disponible para la mayoría de sus capas (Berners-Lee, Hendler \& Lassila, 2001) desde hace una década, y los avances se suceden de forma constante, especialmente en las aplicaciones de datos abiertos enlazados y grafos semánticos (Hitzler, 2021). En particular para el tema que nos ocupa se pueden expresar sistemas de organización del conocimiento en la web semántica mediante RDF, OWL, y específicamente SKOS, una ontología definida como OWL-Full para representar la estructura básica y el contenido de esquemas conceptuales como listas encabezamientos de materia, taxonomías, esquemas de clasificación, tesauros y cualquier tipo de vocabulario controlado (Pastor, Martínez y Rodríguez, 2012; Martínez González y Alvite Díez, 2019).

Por otra parte, el desarrollo de sistemas de recomendación basados en tecnologías semánticas y específicamente ontologías se ha convertido en uno de los campos interdisciplinares más activos entre turismo y ciencia de la información. Ya en su revisión entrada la década anterior $\mathrm{Li}$, Buhalis y Zhang (2013) indicaban que los "Recommender systems based on semantic web and ontology technologies are an effective method and tool to improve the quality of internet service through personalization and customization."

Por la parte de los sistemas de organización del conocimiento, la novedad de la última década ha sido la publicación y consolidación de la nueva norma de tesauros ISO 25964 (Aitchison and Dextre Clarke, 2004; Dextre Clarke, 2012). Frente a otros SOC, los tesauros constituyen la plataforma más general para la interoperabilidad, 
pues comparten con la Internet su naturaleza distribuida y autónoma dentro de unos parámetros normativos claros y operativos de uso e interacción. Destacan por su compromiso entre simplicidad y potencia, y por su gran flexibilidad (García Marco, 2016a): pues son capaces de expresar todas las relaciones fundamentales normativamente creando un marco básico de interoperabilidad mientras que dejan abierta la posibilidad de aplicar modelos más específicos y aún personalizados de relaciones. Finalmente, incorporan el multilingüismo, imprescindible en el entorno web, de forma nativa.

Además de asumir los conceptos como unidades básicas - lo que resuelve de una manera más natural la cuestión multilingüe- y de actualizar y simplificar las anteriores normas en una (ISO, 2011), la parte segunda de ISO 25964 (ISO, 2013) aborda específicamente la interoperabilidad de los tesauros con el resto de SOC, incluyendo taxonomías y ontologías, analizando los diferentes modelos de mapeo y proponiendo herramientas de mapeo específicas $(=E Q, \sim E Q,+$, I, Bm, NM, RM). En principio, los enfoques de hub parecen más adecuados para la generación de mapeos exhaustivos de cara a portales o servicios específicos, aunque los mapeos abiertos están funcionando muy bien para crear grafos abiertos de mucho interés.

La arquitecta del esfuerzo de renovación de los tesauros, Dextre Clarke (2011) realizó muy pronto un diagnóstico preciso de los resultados esperados de los mapeos con diferentes SOC, que es extremadamente relevante para el proyecto presentado en este artículo. Por su parte, Soergel (2010) propuso un modelo conceptual pensando en las búsquedas facetadas que tan populares se han vuelto, por ejemplo, en los sitios de comercio electrónico, también de mucho interés. Como hemos visto en el apartado 3.1 los mapeos que pueden ser más productivos en el caso de la interconexión de sitios de información turística e instituciones de la memoria son, además de los propios tesauros, las listas de encabezamiento de personas, entidades, lugares, títulos y materias por su especificidad respecto a los artefactos culturales y su contexto concreto. Los niveles superiores van a ser siempre difíciles y complejos, pues su estructuración depende de la manera de abordar el dominio por cada agente, lo que no quiere decir que se deban abandonar por imposibles; antes bien, una línea de trabajo necesaria es ir explorando mapeos y proponiendo macrolenguajes de interconexión.

\subsection{Vías de acción}

La interoperabilidad es un problema complicado incluso cuando se intenta entre SOC bien establecidos, pero se vuelve especialmente difícil cuando también se intentan integrar taxonomías web y folksonomías procedentes de los sitios web de los proveedores de información turística y de las redes sociales. Por ello, es necesario encontrar vías prácticas para reducir el espacio del problema y hacerlo abordable. En sendos proyectos pilotos que tenemos en marcha-uno sobre el Camino de Santiago en Aragón y el otro sobre la ruta de Goya en Aragón- se han estado trabajando por el momento en dos direcciones, siempre con el enfoque directo de aprovechar la interoperabilidad semántica para construir y enriquecer sitios web turísticos más funcionales.

En primer lugar, se han estudiado los diferentes tipos de sitios web identificados en la sección 3 - gobiernos regionales y municipales, asociaciones de peregrinos, empresas y particularescon el objetivo de alcanzar un "mínimo común múltiplo" de los conceptos presentes en ellos, mapeando sus relaciones jerárquicas naturales, tal y cómo aparecen en dichos sitios web. De esta forma, los conceptos quedan inventariados en su totalidad pero sin redundancia. A partir de aquí se han controlado los términos equivalentes para permitir un acceso terminológico completo a los usuarios, pues como señalan Xiang, Gretzel y Fesenmaier (2009) es imprescindible recoger el complejo lenguaje del turismo para dar servicios a tipos de turistas muy diferentes. Después se han reducido las relaciones polijerárquicas a una relación monojerárquica preferida y las relaciones asociativas necesarias para representar las alternativas, de forma que se puedan derivar taxonomías. A esta herramienta se están añadiendo mapeos con SOC especialmente relevantes, que toman el carácter de términos equivalentes, específicos o genéricos, y simples o compuestos, según el tipo de mapeo. El resultado es un tesauro multilingüe monojerárquico embebido, compatible con la producción de una taxonomía web simple que pueda servir para el diseño de un sitio web tipo. A este tesauro lo hemos denominado Tesauro Común Taxonómico Compacto (TCTC) (Figura 8 y Figura 9). En el caso de crear un sitio modelo común cada concepto tendría por un lado, un correlato en un nodo o subnodo del CMS subyacente; y una o varias sentencias de búsqueda SPARQL para referir a cada fuente de datos culturales. En este último caso, las sentencias se podrían generar de forma común partiendo del vocabulario codificado en el TCTC y las características comunes de las fuentes externas de datos, con lo que sería 
mucho más fácil extender los mapeos. La capacidad que ha mostrado WikiData para convertirse en un hub semántico también de vocabularios estructurados permitiría minar sus mapeos para ampliar las fuentes de forma automática (García Marco, 2016b). Recíprocamente, de cara a facilitar el servicio de datos enlazados hacia fuera - esto es, no limitarse sólo a utilizar datos externos, sino también servirlos-, bastaría añadir un punto SPARQL al CMS. Las especificidades de este tipo de proyectos están tratadas de forma excelente en otro artículo de este mismo número monográfico (Hernández Carrascal y Agenjo Bullón, 2021).

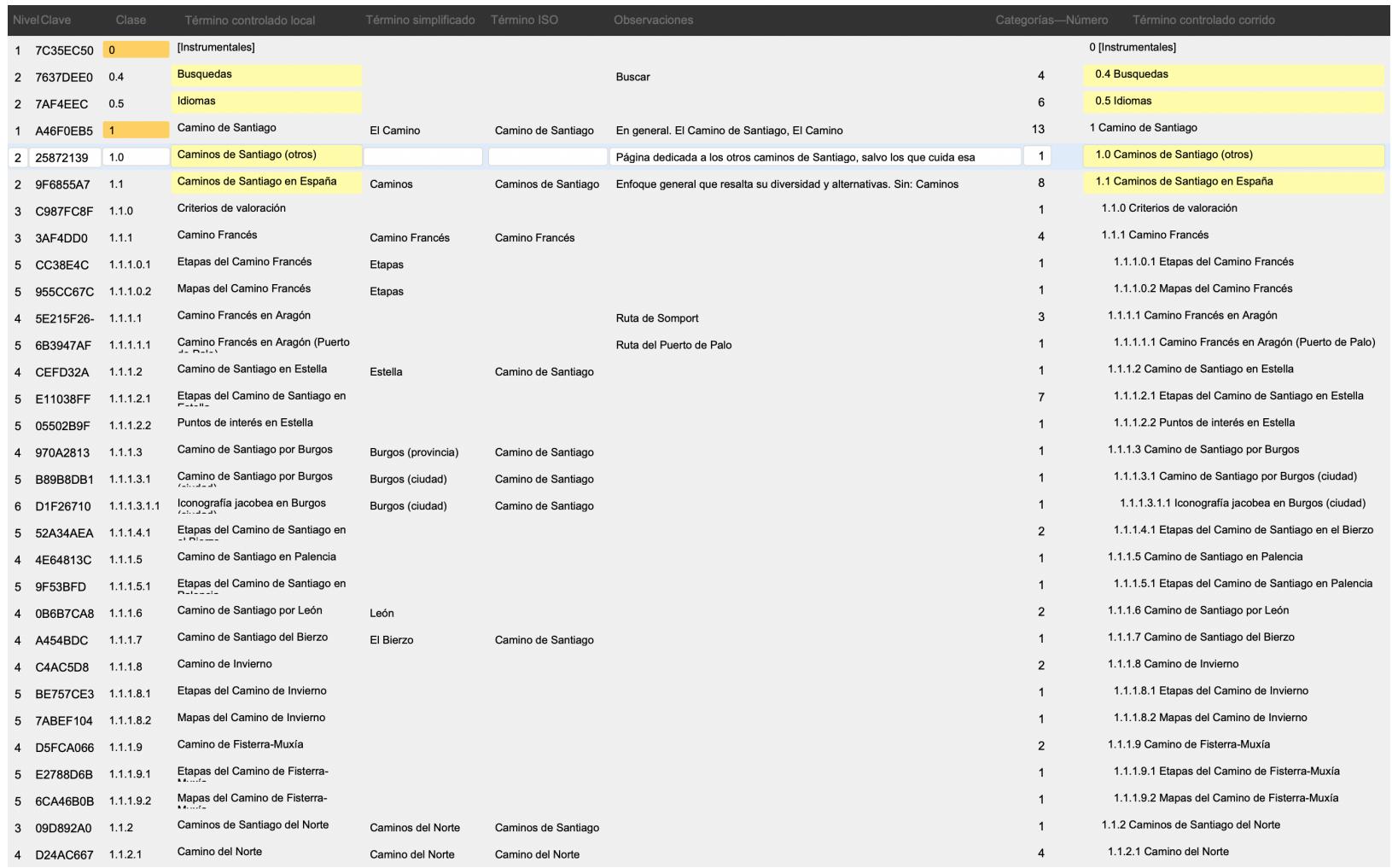

Figura 8. Vista de ejemplo de la base de datos con la taxonomía común construida para las Asociaciones de Amigos del Camino de Santiago

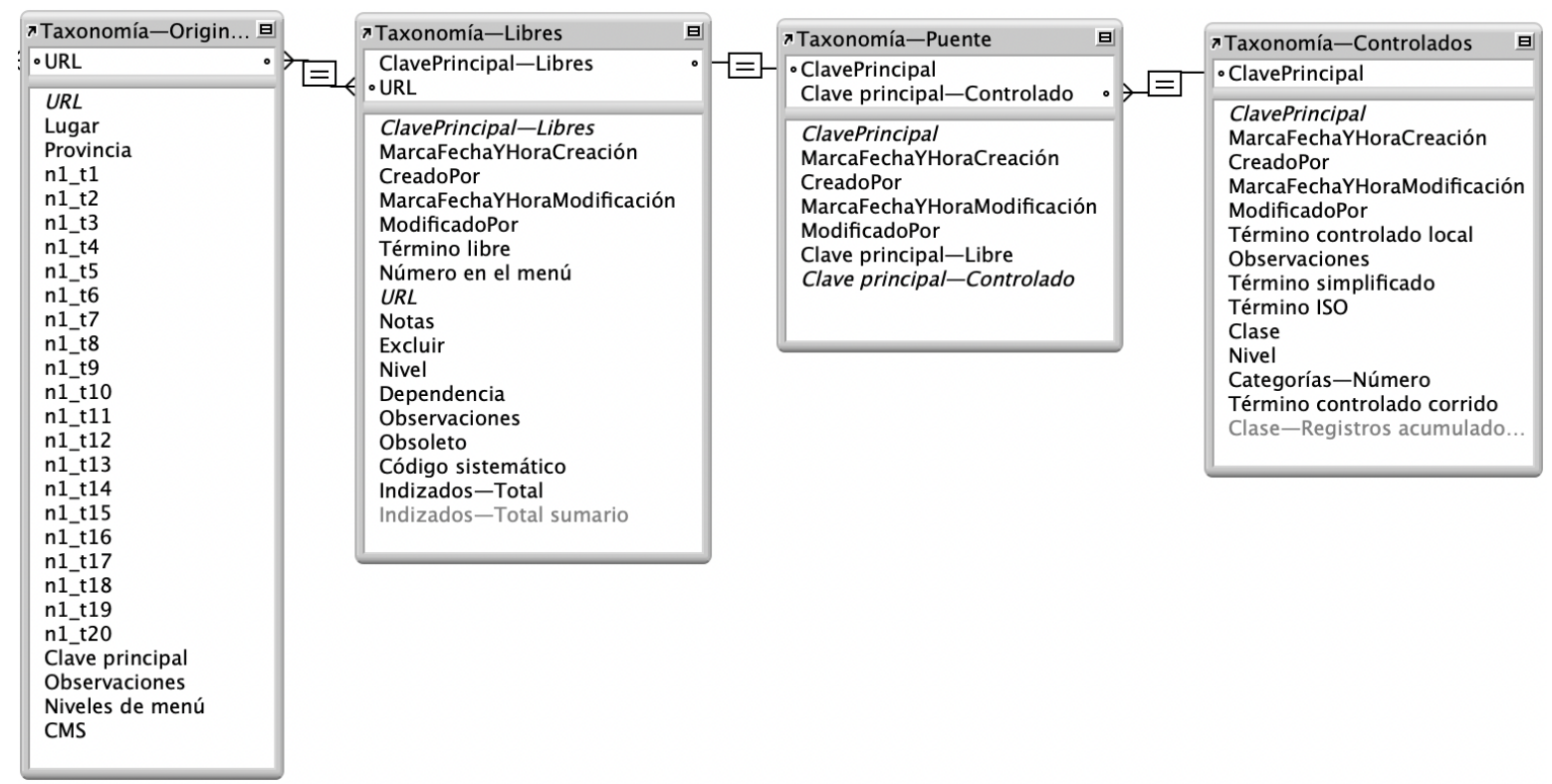

Figura 9. Estructura de la base de datos para controlar los taxones y reexpresarlos

García Marco, Francisco Javier. La organización del conocimiento al servicio de la interconexión entre las instituciones de la memoria y el turismo cultural. // Scire. $27: 1$ (en.-jun. 2021) 55-70. 
En una fase más avanzada se pretende explorar estructuras facetadas y recuperar las polijerarquías para obtener menús adaptados para los diferentes tipos de usuarios. Por el momento se ha aplazado este abordaje, en seguida se vio que en una estructura totalmente facetada la terminología se alejaba mucho de la usada cotidianamente por los usuarios, pues la descoordinación de conceptos complejos para facetarlos genera mucha abstracción y ambigüedad desde el punto de vista del que desea realizar búsquedas específicas. Sí sería posible en el futuro diseñar un sistema facetado que funcionara de forma subyacente para expresar y comunicar diferentes alternativas de organización del dominio turístico en cuestión, como se ha señalado al principio del párrafo.

Por otro lado, se han ido explorando los diferentes KOS existentes en el campo de las instituciones de la memoria para comprobar su potencial para la interoperabilidad con sitios web turísticos. Como hemos visto, una vez mapeada la correspondencia de los diferentes KOS con los nodos de TCTC es posible generar sentencias y filtros de mantenimiento automático. Mapear los lenguajes entre sí y generar de forma general un hub común se demostró una tarea desbordante para pequeños y medianos proyectos, que, además, no resulta productiva en muchos vocabularios debido a la especificidad de la terminología necesaria para servir a los usuarios de sitios e intereses específicos. Díaz-Corona, Lacasta y Nogueras (2021) presentan en este mismo número monográfico los resultados de un mapeo automático del sitio InfoGoya con diversos vocabularios que resulta muy ilustrador al respecto. Lo dicho no invalida que un mapeo en hub que incorpore tanto los KOS de las instituciones de la memoria como de los agentes turísticos pueda constituir un servicio abierto de enorme valor, lo que probablemente se acometerá en un estado de desarrollo más avanzado del dominio que nos ocupa. De hecho el proyecto que se presenta es compatible con su evolución hacia una estructura de este tipo.

Un punto débil de toda esta estrategia es que asume a priori que los SOC de las instituciones de la memoria y de las organizaciones turísticas representan adecuadamente los intereses, conceptos y vocabulario de los usuarios. A esta objeción hay que señalar, por una parte, que la estrategia de mapeo no invalida la necesidad de seguir mejorando los SOC para ajustarlos a sus diferentes tipos de usuarios. Es importante realizar con asiduidad estudios de usuarios tanto subjetivos (satisfacción, entrevistas, etc.) como objetivos (log analysis, search analysis, eye-tracking, entre otros), y de hecho son ya una parte muy importante de las investigaciones en organización del conocimiento. Por otra parte, la propia naturaleza de la labor de mapeo, que pone en contacto sistemas diferentes, sirve para compensar las debilidades de unos sistemas con las fortalezas de otros, ampliando y nivelando el mapa de conceptos resultante.

\section{Conclusiones y perspectivas futuras}

En este artículo se ha intentado presentar un análisis de un campo transdisciplinar emergente de gran interés -la conexión entre industrias de la memoria, editoriales y turísticas mediante tecnologías semánticas-; así como las lecciones ganadas en un caso práctico de aplicación al prototipado de un sitio web de información turística enriquecido con datos culturales, realizando una valoración de sus posibilidades, limitaciones y algunos enfoques alternativos. Se puede concluir que mapear estructuras conceptuales de diferentes dominios, que además pueden ser abordados desde perspectivas de usuario muy diferentes, es un reto difícil, que visibiliza grandes lagunas comparativas entre dominios, y que resulta muy intensivo en trabajo intelectual y humano a pesar de las herramientas tecnológicas disponibles, especialmente si se pretende un ajuste fino. Sin embargo, constituye el futuro de la web y una promesa razonable de mejora -al menos parcial- a los graves problemas de redundancia, dispersión y manipulación de la información que se aprecian en la actualidad.

Sobre todo, se ha intentado mostrar que la interconexión de recursos culturales y necesidades de la industria turística mediante tecnologías semánticas auxiliadas desde la disciplina de la organización del conocimiento es un campo de colaboración transdisciplinar de gran interés para todas las partes implicadas: las instituciones de la memoria pueden ganar en relevancia económica y visibilidad en un entorno de investigación competitivo y muchas veces refractario; la industria turística puede ganar en posibilidades de personalización a una demanda turística cada vez más sofisticada; y las tecnologías semánticas y la organización del conocimiento campos de prueba de gran interés, llenos de retos relevantes y generalizables.

Pero además, este esfuerzo de ajuste fino entre los diferentes sectores implicados constituiría un aporte significativo a la sostenibilidad natural y cultural, ayudando a conectar de forma inteligente demanda y oferta ahorrando recursos, y a preservar la riqueza natural y cultural a través de su comunicación sistemática, pero dirigida, a los usuarios. 
En definitiva, este campo de investigación emergente puede también constituir una gran aportación de la organización del conocimiento como disciplina a un turismo más intensivo y menos extensivo, más respetuoso y comprometido con la sostenibilidad de la naturaleza y las personas, lo que se ha denominado turismo responsable; y demostrar el gran potencial que la organización del conocimiento tiene para aportar metodologías que favorezcan un desarrollo más sostenible en el marco del consenso generado en torno a la Agenda 2030 (Naciones Unidas, 2015).

\section{Agradecimientos}

Este artículo publica resultados de investigación financiados con el proyecto CSO2015-65448-R (MINECO/FEDER). Se agradece sinceramente el apoyo a las instituciones financiadoras sin cuya generosidad esta investigación no hubiera sido posible.

\section{Referencias}

Abrahams, Brooke and Wei Dai (2005). Architecture for Automated Annotation and On-tology Based Querying of Semantic Web Resources. // 2005 IEEE/WIC/ACM International Conference on Web Intelligence, Proceedings, 413417

Aitchison, Jean and Stella Dextre Clarke (2004). The Thesaurus: A Historical Viewpoint, with a Look to the Future. Cataloging \& Classification Quarterly. 37, 5-21.

Bechmann Pedersen, S. (2020). A Passport to Peace? Modern Tourism and Internationalist Idealism. // European Review. 28:3, 389-402. doi:10.1017/S106279871 9000516

Berners-Lee, T.; Hendler, J.; O. Lassila (2001). The semantic web. // Scientific American. 284:5, 76-88

Csapó, Janos (2012). The Role and Importance of Cultural Tourism in Modern Tourism Industry. // Strategies for Tourism Industry: Micro and Macro Perspectives, edited by Murat Kasimoglu and Handan Aydin. London: IntechOpen. 201-232.

Dahlberg, Ingetraut (1995). Current trends in knowledge organization. // Organización del conocimiento en sistemas de información y documentación : actas del I Encuentro de ISKO-España, Madrid, 4 y 5 de noviembre de 1993 (pp. 7-26): Zaragoza : [ISKO-España : Universidad de Zaragoza]. http://www.iskoiberico.org/wp-content/uploads/ 2014/07/007-026 Dahlberg.pdf

Debbage, Keith $\left(2018^{\mathrm{a}}\right)$. Economic Geographies of Tourism: A Critical and Contested Discourse. // The SAGE Handbook of Tourism Management. London: SAGE. 53-68.

Debbage, Keith (2018b). Economic Geographies of Tourism: One 'Turn' Leads to Another. // Tourism Geographies. 22, 347-353.

Dextre Clarke, Stella G. (2011). In Pursuit of Interoperability: Can We Standardize Map-ping Types?. // Concepts in Context: Cologne Conference on Interoperability and Semantics in Knowledge Organization; held 19-20 July 2010; Cologne, Germany, edited by F. Boteram, W. Goedert, and J. Hubrich. Würzburg: Ergon Verlag.

Dextre Clarke, Stella G. (2012). ISO 25964: A Standard in Support of KOS Interoperability. // Facets of Knowledge Organization, 4-5 July 2011, London / eds. Alan Gilchrist and Judi Vernau. London: Emerald, 129-134.

Díaz-Corona, Dayany; Lacasta, Javier; Nogueras Iso, Javier (2021). Enriquecimiento automático de portales culturales mediante modelos de organización del conocimiento. // Scire. 27:1

Fang, Wei Tang (2020). Tourism in Emerging Economies: The Way We Green, Sustainable, and Healthy. Singapore: Springer.

García Marco, Francisco Javier (2010). Las instituciones de la memoria ante el cambio digital: una propuesta sobre la articulación interdisciplinar de las ciencias de la documentación. // Pliegos de Yuste: revista de cultura y pensamiento europeos. 11-12, 61-70.

García Marco, Francisco Javier (2015). Apropiación y uso de la información y del conocimiento en el contexto de las ecologías informacionales. // González de Gómez, Maria Nélida; Rabello, Rodrigo (org.). Informação: agentes e intermediação. Brasília: IBICT, 2015. p. 313-353. http://livroaberto.ibict.br/handle/123456789/1068. ISBN 978-857013-107-2.

García Marco, Francisco Javier (2016a). The evolution of thesauri and the history of knowledge organization: Between the sword of mapping knowledge and the wall of keeping it simple. // Brazilian Journal of Information Studies: Research Trends. 10:1, 1-11. http://www2.marilia.unesp.br/revistas/index.php/bjis/article/view/5786.

García Marco, Francisco Javier (2016b). Enhancing the visibility and relevance of thesauri in the web: searching for a 'hub' in the linked data environment. // Knowledge Organization. 43:3, 193-202.

García-Marco, Francisco Javier; Galindo, Fernando; Lasala, Pilar; López del Ramo, Joaquín (2020). Advancing the Interoperability of the GLAM+ and Cul- tural Tourism Sectors through KOS. // Advances in Knowledge Organization. 17, 151-160. doi.org/10.5771/9783956507762-151. https://www.ergon-verlag.de/isko_ko/downloads/aiko_vol_17_2020_18.pdf

Given, L., M. And McTavish, L. (January 2010). What's Old Is New Again: The Reconvergence of Libraries, Archives, and Museums in the Digital Age. // The Library Quarterly. 80:1, 7-32. http://www.jstor.org/stable/10.1086/648461 .

Gretzel, Ulrike, Yeong-Heyon Hwang, and Daniel R. Fesenmaier (2006). A Behavioural Framework for Destination Recommendation Systems Design. // Destination Recommendation Systems: Behavioural Foundations and Applications, edited by D. R. Fesenmaier, K. Wöber and H.Werthner. Wallingford, UK: CABI, 53-64.

Grün, Christoph, Julia Neidhardt, and Hannes Werthner (2017). Ontology-Based Match-making to Provide Personalized Recommendations for Tourists. // Information and Communication Technologies in Tourism 2017, edited by R. Schegg and B. Stangl B. Cham.: Springer, 3-16.

Hernández Carrascal, Francisca; Agenjo Bullón, Xavier (2021). El turismo cultural y la digitalización del patrimonio en un entorno Linked Open Data: el caso de Europeana. // Scire. 27:1.

Hitzler, Pascal (2021). A review of the semantic web field. // Communications of the ACM. 64:2, 76-83. https://doi.org/10.1145/3397512

Hjerppe, R. A. (1994). A framework for the description of generalized documents. // Advances in Knowledge Organization. 4, 173-180.

Hjørland, B. (2000). Documents, memory institutions and information science. // Journal of Documentation. 56:1, 2741. DOI: $10.1108 / E U M 0000000007107$.

Hjørland, Birger (2017). Domain analysis. // Knowledge Organization. 44: 6, 436-464. https://www.isko.org/cyclo/domain_analysis

Hjørland, Birger; Albrechtsen, Hanne (1995). Toward a new horizon in information science: Domain analysis. // Journal of the American Society for Information Science. 46: 6, 400-425. 
Huberman, B. A. (2001). The laws of the web: patterns in the ecology of Information. Cam-bridge, Mass.: MIT Press.

ISO (2011). ISO 25964-1:2011. Information and documentation. Thesauri and interoper-ability with other vocabularies. Part 1: Thesauri for information retrieval. Geneva: ISO

ISO (2013). ISO 25964-2:2013. Information and documentation. Thesauri and interoper-ability with other vocabularies. Part 2: Interoperability with other vocabularies. Geneva: ISO.

Laslett, Peter (1965). The world we have lost: England before the industrial age. London: Methuen.

Li, Nao; Buhalis, Dimitrios; Zhang, Lingyun (2013). "nterdisciplinary Research on Information Science and Tourism. // Information and Communication Technologies in Tourism 2013, edited by L. Cantoni and Z. Xiang. Berlin, Heidelberg: Springer, 302-313

López del Ramo, Joaquín; García Marco, Francisco Javier (2018). El Camino de Santiago en los sitios web de las Comunidades Autónomas: análisis del Contenido, orientación y encuadres temáticos predominantes. // Revista General de Información y Documentación 28, 703-26.

Lowry, Linda L. (2017). Introduction. // Lowry, Linda L. (ed.). The SAGE international enciclopedia of travel and tourism. Thousand Oaks, Ca.: SAGE, 2017. Xxxiii-xliii.

Martínez González, María Mercedes; Alvite Díez, María Luisa (2019). Thesauri and Semantic Web: Discussion of the evolution of thesauri toward their integration with the Semantic Web. IEEE Access. 7. DOI: 10.1109/ACCESS.2019.2948028

Maslow, Abraham H. (1954). Motivation and personality. New York: Harper.

McKercher, B.; Du Cross, Hilary C. (2002). Cultural Tourism: The Partnership Between Tourism and Cultural Heritage Management. New York: Hayworth Hospitality Press.

Naciones Unidas (2015). Transforming our world: the 2030 Agenda for Sustainable Development: Resolution adopted by the General Assembly on 25 September 2015 (A/RES/70/1). New York: Naciones Unidas. https://en.wikipedia.org/wiki/File:N1529189.pdf.

Pandur, loana (2013). Types of Cultural Tourism. // Scientific Papers: Animal Science and Biotechnologies. 46:1, 385388.

Pastor-Sánchez, Juan Antonio; Martinez-Mendez, FranciscoJavier; Rodríguez, J. V. (2012). Aplicación de SKOS para la interoperabilidad de vocabularios controlados en el entorno de linked open data. // El Profesional de la Informacion. 21:3,245-253. DOI: 10.3145/epi.2012.may.04
Petroman I.: Petroman, Cornelia; Marin, Diana; Ciolac, Ramona; Văduva, Loredana;

Ranganathan, S. R. (1937). Prolegomena to library classification. Madras, London: The Madras library association; E. Goldston, Itd.

Sebastiá, Montserrat (2008). La Ecología de la Información: Un Nuevo Paradigma de la Infoesfera. // Pliegos de Yuste. 7-8: 24-36.

Shim, Seonyoung and Byungtae Lee (2006). Evolution of Portals and Stability of Infor-mation Ecology on the Web. /I Proceedings of the 8th International Conference On Electronic Commerce. New York: ACM, 584-588.

Slavic, Aida (2011). Classification Revisited: A Web of Knowledge. // Innovations in Information Retrieval: Perspectives for Theory and Practice, Eds. Allen Foster and Pauline Rafferty. London: Facet. 23-48

World Tourism Organization (2001). Thesaurus on Tourism \& Leisure Activities (Trilingual: English, French, Spanish) Madrid: World Tourism Organization.

World Tourism Organization (2012). Summary study on tourism and intagible cultural heritage. Madrid: UNWTO. https://doi.org/10.18111/9789284414796.

World Travel \& Tourism Council (2020). Travel \& tourism global economic impact \& trends 2020. WTTC, June 2020 https://wttc.org/Portals/0/Documents/Reports/2020/Global\%20Economic \%20Impact $\% 20$ Trends\%202020.pdf? ver=2021-02-25-183118-360 (2021-05-04).

World Travel \& Tourism Council (2021a). Economic Impact Reports. https://wttc.org/Research/Economic-Impact (2021-05-04).

World Travel \& Tourism Council (2021b). Spain 2021 Annual Research: Key Highlights. https://wttc.org/Research/Economic-Impact/moduleld/704/itemld/206/controller/DownloadRequest/action/QuickDownload (2021-05-04).

Xiang, Zheng, Gretzel, Ulrike; Fesenmaier, Daniel R. (2009). Semantic Representation of Tourism on the Internet. // Journal of Travel Research. 47, 440-53.

Xiang, Zheng, Dan Wang, Joseph T. O'Leary, and Daniel R. Fesenmaier (2015). Adapting to the Internet: Trends in Travelers' Use of the Web for Trip Planning. // Journal of Travel Research. 54, 511-27.

Zeng, Marcia Lei (2019). Interoperability. // Knowledge Organization. 46:2, 122-146. http://www.isko.org/cyclo/interoperability.

Enviado: 2021-06-09

Aceptado: 2021-06-16. 